\title{
Fostering weather and climate literacy among pupils by engagement in a weather citizen science project
}

\author{
Thomas Kox,,$^{a, b, *}$ Martin Göber, ${ }^{b, c}$ Bianca Wentzel,,${ }^{b, d}$ Elisabeth Freundl ${ }^{e}$ and \\ Henning W. Rust ${ }^{b, d}$ \\ ${ }^{a}$ Department of Geography, Ludwig-Maximilians-Universität München, \\ Luisenstr. 37, Munich, Germany \\ ${ }^{b}$ Hans-Ertel-Centre for Weather Research, \\ Berlin, Germany \\ ${ }^{c}$ Deutscher Wetterdienst, \\ Frankfurter Str. 135, Offenbach am Main, Germany \\ ${ }^{d}$ Institute of Meteorology, Freie Universität Berlin, \\ Carl-Heinrich-Becker-Weg 6-10, Berlin, Germany \\ ${ }^{e}$ Energiewende Oberland, \\ Am Alten Kraftwerk 4, Penzberg, Germany \\ E-mail: t.kox@lmu.de, martin.goeber@dwd.de, bianca.wentzel@fu-berlin,de, \\ freundl@energiewende-oberland.de, henning.rust@fu-berlin.de
}

The project KARE-citizen science established a layperson weather network with two schools in the Bavarian Prealps, Germany, to build up decision-relevant knowledge about weather and climate. Over the summer of 2020, pupils collected weather data with self-assembled low-cost autonomous weather stations and reported weather impacts. The project included a pre- and post-test of pupils' weather literacy and awareness of climate change and their expectation of local weather before summer and perception in hindsight. The ongoing COVID-19 situation had a major impact on the intended activities. A comprehensive analysis is therefore deferred to a full experiment planned in summer 2021.

Vienna - Austria

\footnotetext{
*Speaker
} 


\section{Introduction}

In recent years urban floods, heavy rainfall and severe winter storms have made it clear how exposed and vulnerable people and infrastructures are to the impacts of extreme weather. Climate change will very likely intensify these effects in the future. However, the ability to perceive weather risks, to interpret forecasts and warnings correctly and to use them for decisions and actions vary. Despite good forecasts and warnings available, people often misjudge weather information and do not react appropriately to protect themselves or their belongings [1]. In order to make decisions and take protective measures, understanding weather and weather forecasts is of central importance. Improving the understanding of weather risks, impacts and forecast uncertainty has become a major concern of weather services as well as national and international research [2].

Effective risk communication is a fundamental prerequisite in order to involve citizens in risk reduction initiatives and to foster public risk perception. Without an awareness of risks, no targeted and effective personal provision and informed decision can be made. Various studies therefore call for measures to remedy this deficit, e.g. by anchoring natural hazards and weather risks as well as topics of personal provision in school curricula [3]. Challenges of climate education result in particular from the complexity of the topic as well as from a perceived temporal and spatial detachment to the impacts of climate change [4]. The involvement of pupils in research projects using a citizen science approach seem to be a promising approach to deal with these difficulties [4].

In the course of a project on climate change adaptation at the regional level (KARE ${ }^{1}$ ), a citizen science component was created to facilitate the activation of the population for climate change adaptation and increase public understanding of weather risks. In KARE-Citizen Science a lay weather network was set up together with pupils in the Bavarian Prealps, Germany. The pupils assembled autonomous weather stations and measured temperature and precipitation in their direct environment. They also had the opportunity to record weather impacts such as observed damages or impairments felt. Together with their teachers and project partners, these data were evaluated.

KARE-Citizen Science focuses on upper secondary school pupils as participants and aims at the development of competences among teachers and pupils particularly in terms of climate change adaptation, understanding of natural hazards and risks and in taking personal precautions. The project included a pre and post-test of pupils' weather literacy and awareness of climate change [1] and their expectation and perception of the local weather in summer 2020.

\section{Assembling MESSI - Adopting MESSI}

MESSI, derived from "messen", the German word for measuring, is the nickname of the selfassembled low-cost autonomous weather station designed for the project. Inspired by the Maker culture, it is based on Internet-of-things-technology and parts from a 3D-printer which makes it attractive to pupils. MESSI (Fig. 1) operates on battery supported by solar power and wirelessly transmits temperature, pressure, humidity, solar radiation and rainfall via the LoRaWAN protocol every few minutes. Supported by detailed instructions and video conferencing, the pupils assembled their MESSIs during about $1.5 \mathrm{~h}$ as a process to adopt the device. After installing the MESSI outside, its measurements (and those of nearby MESSIs) are quasi instantaneously visualised via a

\footnotetext{
1http://www.klimaanpassung-oberland.de/
} 
web-application particularly developed for this purpose. Using online digital teaching materials

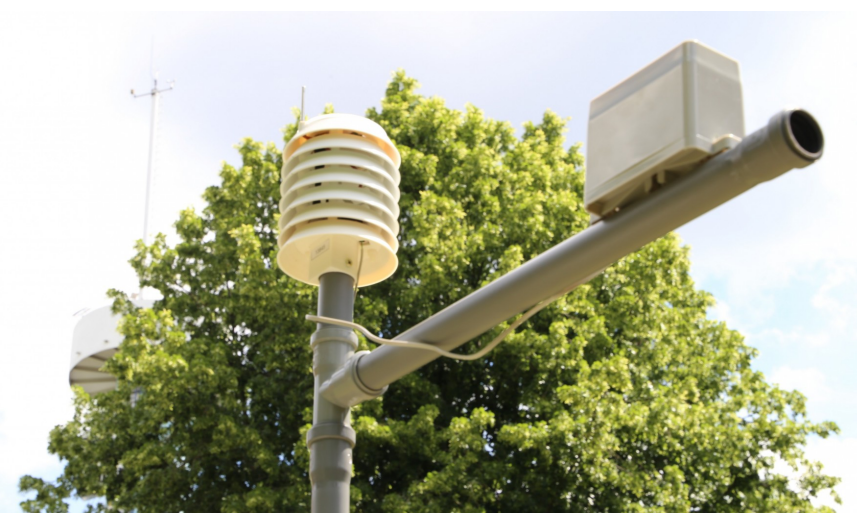

Figure 1: MESSI with attached tipping bucket rain gauge to collect precipitation, Photo: Andreas Trojand. This work is licensed under a Creative Commons Attribution-NonCommercial-NoDerivs 3.0 Germany (CC BY-NC-ND 3.0 DE) License.

(explanatory movies, recorded lectures, songs and games ${ }^{2}$ ) and online workshops, the pupils were introduced to the functioning of the weather station, the inherent problems of weather forecasting (nonlinear system with uncertain initial conditions), the resulting need for probabilistic forecasts and their interpretation. MESSI's atmospheric measurements are supplemented by pupils' reports on observed weather events and local weather impacts in terms of their severity, possible damages and felt impairments.

\section{Preliminary Survey Results from Summer 2020}

The measurements took place between June and November 2020 with two schools in the Bavarian Prealps. Due to the ongoing COVID-19 situation, a reduced number of 23 pupils (8th12th grade; age 14-18) participated voluntary aside from their usual school activities with the support of their teachers. The pupils were recruited from environmental school clubs and voluntary groups. They took care of 25 MESSIs (two of the pupils shared one device). A control group of 19 pupils (same schools and age group) voluntarily took the tests without participating in the project. The questions were asked anonymously in an online survey alongside two online workshops in June and November. The overall response rate was 39 of 42 for the pre-test and 26 of 42 for the post-test.

\subsection{Weather Literacy and Awareness of Climate Change}

Weather literacy is understood as the ability to understand basic weather-related risks in order to be able to anticipate and prepare for severe weather [1]. The pupils were asked 12 factual questions about thunderstorms, rain and heat events (see Tab. 1), and 6 questions about climatic changes (increase, decrease, or unchanged) since 1880 in annual mean temperature, average amount of rain per year and the severity of storms (see Tab. 2). All questions were taken from Fleischhut et al. (2020), who developed them in a nationally representative survey of the public [1]. The results of this survey are used as a reference for comparison here. Due to the pandemic restrictions, our

${ }^{2}$ Material available at https://www.geo.fu-berlin.de/met/wexicom/MESSI, in German only. 
sample size is too small to draw conclusions from comparing pre- and post-test. We thus need to defer this question to a full experiment planned in summer 2021. For now, we combine the pre-test of the project and control group to compare with the literature.

\begin{tabular}{|c|c|c|c|c|}
\hline \multirow[b]{2}{*}{ Topic } & \multirow[b]{2}{*}{ Item } & \multirow[b]{2}{*}{ True Answer } & \multicolumn{2}{|c|}{ Percent Correct } \\
\hline & & & Pupils & Public [1] \\
\hline Thunderstorm & $\begin{array}{l}\text { How far away is a thunderstorm if there is a } \\
30 \text {-second gap between the lightning and the } \\
\text { thunder? }\end{array}$ & $10 \mathrm{~km} \pm 2 \mathrm{~km}$ & $56^{* * *}$ & 24 \\
\hline Thunderstorm & $\begin{array}{l}\text { Thunderstorms occur most frequently in au- } \\
\text { tumn. }\end{array}$ & False & $97^{* * *}$ & 69 \\
\hline Thunderstorm & $\begin{array}{l}\text { Thunderstorms can develop from harmless- } \\
\text { looking clouds within } 10 \text { to } 15 \text { minutes. }\end{array}$ & Correct & 85 & 78 \\
\hline Thunderstorm & $\begin{array}{l}\text { Thunderstorms can move with a speed up to } \\
100 \mathrm{~km} / \mathrm{h} \text {. If a thunderstorm is } 10 \mathrm{~km} \text { away, } \\
\text { it will take less than } 6 \text { minutes to arrive. }\end{array}$ & Correct & 87. & 77 \\
\hline Thunderstorm & $\begin{array}{l}\text { Lightning often strikes } 10 \mathrm{~km} \text { away from a } \\
\text { storm }\end{array}$ & Correct & $21^{* * *}$ & 56 \\
\hline Rain & $\begin{array}{l}\text { Intense rainfall occurs most frequently in } \\
\text { spring }\end{array}$ & False & $77^{*}$ & 59 \\
\hline Rain & $\begin{array}{l}\text { Floods can also occur if there is no stream, } \\
\text { river, or lake nearby }\end{array}$ & Correct & 79 & 78 \\
\hline Rain & $\begin{array}{l}\text { Intense rainfall can cause flash floods and } \\
\text { flooding within just a few minutes }\end{array}$ & Correct & $59^{*}$ & 78 \\
\hline Rain & $\begin{array}{l}\text { The shorter the period of time in which } 20 \\
\text { liters of rain per square meter fall, the greater } \\
\text { the danger of flash floods and flooding }\end{array}$ & Correct & $46^{* * *}$ & 89 \\
\hline Heat & $\begin{array}{l}\text { Daytime temperatures tend to be highest in } \\
\text { the afternoon }\end{array}$ & Correct & 77 & 81 \\
\hline Heat & $\begin{array}{l}\text { At temperatures above } 30 \text { degrees [Celsius], } \\
\text { the body can lose several liters of water per } \\
\text { day through sweating }\end{array}$ & Correct & $62^{* * *}$ & 86 \\
\hline Heat & $\begin{array}{l}\text { The higher the humidity level, the harder it is } \\
\text { for people to deal with the heat }\end{array}$ & Correct & $74^{* *}$ & 90 \\
\hline
\end{tabular}

Table 1: Pupils' understanding of weather risks. Percent correct pre-test answers of combined participants and control group $(\mathrm{n}=39)$, items based on [1]. Superscripted are $p$-values from a two-sided binomial test

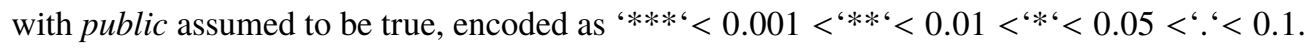

The results in Tab. 1 show that the pupils generally have a good sense of weather risks compared to the public sample. Whether the age of the pupils plays a role in the correct answers, i.e. experience of weather events, cannot be determined.

Tab. 2 shows a much higher knowledge of the observed climatic change in temperature by the pupils compared to the general public. If the presence of the "Fridays for Future movement" could have had an influence on the understanding of this issue is speculative and requires further analysis.

\subsection{Weather Event Frequency during Summer 2020}

In the introductory workshop before the MESSIs were built, the pupils were also asked how they would expect the frequency of certain weather events in their region for the coming summer. 


\begin{tabular}{|c|c|c|c|c|}
\hline \multirow[b]{2}{*}{ Topic } & \multirow[b]{2}{*}{ Item } & \multirow[b]{2}{*}{ True Answer } & \multicolumn{2}{|c|}{ Percent Correct } \\
\hline & & & Pupils & Public [1] \\
\hline Rain & $\begin{array}{l}\text { How has the average amount of precipitation } \\
\text { per year changed? }\end{array}$ & Higher & 31 & 45 \\
\hline Rain & $\begin{array}{l}\text { How has the number of days per year with at } \\
\text { least } 10 \mathrm{l} / \mathrm{m}^{2} \text { changed? }\end{array}$ & Unchanged & $21^{\circ}$ & 35 \\
\hline Temperature & $\begin{array}{l}\text { How has the number of hot days (above } 30^{\circ} \mathrm{C} \text { ) } \\
\text { per year changed? }\end{array}$ & Higher & $100^{* * *}$ & 58 \\
\hline Temperature & $\begin{array}{l}\text { How has the number of cold days (below } 0^{\circ} \mathrm{C} \\
\text { during daytime) per year changed? }\end{array}$ & Lower & $74^{*}$ & 57 \\
\hline Temperature & How has mean temperature per year changed? & Higher & $95^{* * *}$ & 70 \\
\hline Wind & How has the severity of storms changed? & Unchanged & 18 & 16 \\
\hline
\end{tabular}

Table 2: Pupils' awareness of climate change. Percent correct pre-test answers of combined participants and control group ( $\mathrm{n}=39)$, items based on [1]. Superscripted are $p$-values from a two-sided binomial test with

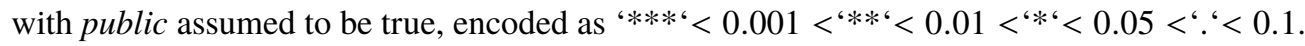

This question was asked again in the post-test, this time asking how they perceived the frequency of weather events in hindsight. The period covered was the regional summer holiday season (42 days from 27 July to 7 September 2020). The questions related to the frequency of thunderstorms, heavy rain and cold and hot days, as well as the temperature maximum and minimum. The answers were compared with the actual regional weather of that time and regional climatological data of the German weather service DWD (see Tab. 3).

\begin{tabular}{lcccc}
\hline & \multicolumn{2}{c}{ Pupils } & \multicolumn{2}{c}{ DWD } \\
Statement & Expectation* & Hindsight** & 2020 & Climate \\
\hline There will be thunderstorms on $\ldots$ out of 42 days. & 10 & 9 & 4 & 17 \\
On $\ldots$ of 42 days it will rain so hard that the water will stand on the street. & 4 & 6 & 7 & - \\
On the warmest day it will be $\ldots{ }^{\circ} \mathrm{C}$. & $36^{\circ} \mathrm{C}$ & $37^{\circ} \mathrm{C}$ & $33^{\circ} \mathrm{C}$ & $33^{\circ} \mathrm{C}$ \\
On $\ldots$ out of 42 days it will be $30^{\circ} \mathrm{C}$ or hotter. & 20 & 23 & 4 & 2 \\
On the coldest night it will be $\ldots{ }^{\circ} \mathrm{C}$. & $7^{\circ} \mathrm{C}$ & $9^{\circ} \mathrm{C}$ & $7^{\circ} \mathrm{C}$ & $7^{\circ} \mathrm{C}$ \\
On $\ldots$ out of 42 days it will be $10^{\circ} \mathrm{C}$ or colder at night. & 8 & 6 & 7 & 7 \\
\hline
\end{tabular}

Table 3: Pupils' expectation of frequency of weather events before regional summer holidays 2020 and perception in hindsight (median values, $* \mathrm{n}=39, * * \mathrm{n}=26$ ), and mean values for regional summer holidays 2020 and regional climatological data of three DWD stations (Hohenpeißenberg, Holzkirchen, Attenkam).

Pupils' expectations as well as their perceptions for a large part of the weather events match the actual observations of the DWD relatively well in comparison. Two entries are striking. Firstly, the pupils expected fewer days with thunderstorms for the summer than climatologically expected according to DWD data. In hindsight, they perceived more thunderstorms than actually occurred. Note that the occurrence of thunderstorms during this period was only a quarter of climatological expectancy. Secondly, and very noticeably, the pupils, both before and after the summer, give very high values for the frequency of hot days $\left(>30^{\circ} \mathrm{C}\right)$ and the maximum temperature in comparison to the DWD data. The indication of the frequency of hot days is particularly remarkable. We speculate, that a lower level of knowledge regarding heat is not responsible, as a comparison with the weather literacy answers indicates (see Tab. 1). As Fleischhut et al. point out, the understanding of weather 
risks and the awareness of climate change seem to represent two different kinds of knowledge [1]. Whether a recency bias favouring particularly hot summers in recent years influenced these statements also remains open. Although the number of hot days in the last three summer school holidays was somewhat higher than climatologically expected $\left(3,8,3\right.$ days $\left.>30^{\circ} \mathrm{C}\right)$, these values are also clearly below the expectations and perceptions of the pupils. It cannot be ruled out that they did not only refer to the school holidays, but to the entire summer.

\section{Outlook}

The results of the pre-test in comparison to the reference are interesting, but further conclusions are hampered due to the small number of participants and expected high variance due to external influences during the COVID-19 pandemic. In a next step, we want to evaluate to what extent participation leads to an increase in weather and climate risk competence among participants, their interests in science subjects (STEM) or weather in general. The analysis is still ongoing.

\section{Acknowledgments}

This research was part of the project KARE-Citizen Science funded by the BMBF (German Federal Ministry of Education and Research) under the grand agreement 01LR2009A. Martin Göber's research was carried out in the framework of the Hans-Ertel-Centre for Weather Research funded by the BMVI (German Federal Ministry of Transport and Digital Infrastructures) under the grand agreement 4818DWDP3A. The authors would like to thank all participating pupils, teachers, and local technical support in Berlin and Bavaria.

\section{References}

[1] N. Fleischhut, S.M. Herzog and R. Hertwig, Weather Literacy in Times of Climate Change, Weather, Climate, and Society 12 (2020) 435.

[2] A. Taylor, T. Kox and D. Johnston, Communication high impact weather: Improving warnings and decision making process, International Journal of Disaster Risk Reduction 30, Part A (2018) 1.

[3] S. Rohland, C. Pfurtscheller, S. Seebauer and A. Borsdorf, Muss die Eigenvorsorge neu erfunden werden? Eine Analyse und Evaluierung der Ansätze und Instrumente zur Eigenvorsorge gegen wasserbedingte Naturgefahren (REInvent). Endbericht von StartClim2015.A, in StartClim2015: Weitere Beiträge zur Umsetzung der österreichischen Anpassungsstrategie, (Vienna), BMLFUW, BMWF, ÖBf, Land Oberösterreich (2016).

[4] S. Brumann, U. Ohl and C. Schackert, Researching Climate Change in Their Own Backyard_Inquiry-Based Learning as a Promising Approach for Senior Class Students, in Climate Change and the Role of Education, W. Leal Filho and S.L. Hemstock, eds., Climate Change Management, (Cham), pp. 71-86, Springer International Publishing (2019), DOI. 